\title{
Automatic Devices: The Next Frontier of Cardiopulmonary Resuscitation?
}

\author{
Carlo Remino* \\ Department of Mechanical and Industrial Engineering, University of Brescia, Italy
}

Submission: March 20, 2018; Published: May 01, 2018

*Corresponding author: Carlo Remino, Department of Mechanical and Industrial Engineering, University of Brescia, Via Branze 38, 25123, Brescia, Italy, Email: carlo.remino@unibs.it

\section{Opinion}

To be effective, Cardio Pulmonary Resuscitation (CPR) requires a prompt and correct execution with compressions having the depth and the rate prescribed by the AHA. Unfortunately, the human chest dissipates most of the energy applied during the massage, consequently rescuers need to change frequently not to allow the fatigue to impair their performance. But, the recurrent interruption of the massage reduces the effectiveness of the resuscitation even further. This is the raisons d'être of the automatic devices: to overcome the negative effect of fatigue and interruptions.

The AHA does not recommend the routine use of automatic devices, because there is no statistical evidence that they improve the outcome of CPR [1-8]. However, statistics tell only part of the story. Forti et al. [9], for example, have described the case of a man who survived a cardiac arrest without neurological impairment: a man who would have been declared dead if no automatic devices would had been available at the scene, because the transportation by helicopter and ambulance would have required more than 30 min.

The ability to massage with the prescribed depth and rate during transportation is one of the distinct advantages the automatic devices have over manual CPR, because the massage is usually performed in cramped or unsafe conditions. But automatic devices can also massage during defibrillation and other operations, or when a manual massage is difficult or impossible to do, as during PCI, ECMO, diagnostic imaging, or organ transplantations. Finally, requiring no or little attendance, they allow the rescuers to perform complementary tasks.

The automatic devices can be classified according to their working principle. All of them convert electric or pneumatic energy into mechanical energy for compressing or squeezing the thorax. Most act on the sternum with a piston, applying a force in the same way manual CPR does. The better-known device in this category is the Lucas. On the contrary, Autopulse and the Vest system apply a pressure: the former on the chest; the latter on all the thorax. Each solution has advantages and disadvantages [10]. Wrapping the thorax and squeezing it, the Vest is theoretically the best solution, because: 1) it does not require a rigid plate to be effective; 2) it has a smaller transversal section, therefore it is more suitable for being used during diagnostic imaging; 3 ) it needs to compress the chest to a lesser extent to change its volume of the amount required to generate significant hemodynamics effects. The Autopulse has the advantages 2) and 3), while the devices with a piston mounted on an arm, as the Life-Stat, allow free access to the patient.

Compressing the chest is not the only way to stimulate circulation. Interposed abdominal compression CPR, for example, alternates abdominal compressions to chest compressions. This alternate stimulation not only doubles the flow [11-13], but requires a lesser depth of compression, which reduces the danger of ribs and sternum injuries. However, because the abdomen is softer than the thorax, caution need to be exercised in compressing it to prevent injuries to vital organs. Other experimental methods generate or are intended to generate hemodynamic effects without exerting mechanical forces or pressures. The pGz device circulates blood in the cardiovascular and pulmonary systems by inertial forces generated by periodic acceleration along the patient's spinal axis [14]. The EMCPR (Expulsive Maneuvre CPR) device uses magnetic impulses to stimulate the rhythmic contraction of the diaphragm and the abdominal muscles to pump blood from the abdomen $[15,16]$.

The most important requirement for a CPR device is easy of set-up and placement, so that the hand-off time could be kept to a minimum, and with it the corresponding loss of coronary perfusion pressure [17]. For this reason an automatic device should have a design thought to be simple and ergonomic. In this respect, the application of a force on the sternum is preferable to the application of a pressure to all the thorax or part of it, because the compressing element need to be applied in only one point. However, the hand-off time depends not only on the configuration of the device, but also on the training of the rescuers and how they 
work as a team. According to Ong et al. [18], the quality of CPR delivered with automatic devices can be significantly improved if each member of the team is drilled in a specific role at a specific place.

However, too many factors influence the outcome of CPR, and some of them are set before the beginning of the resuscitation attempt. It is the global response to all these factors that decides if the outcome will be a success or a failure. Even if it was true that the automatic CPR is still not as cost effective as the manual CPR when it is concerned not only the cost of the intervention, but also the cost of the services delivered during and after hospitalization $[4,19]$, nevertheless their constant use allow gaining a high level of proficiency and developing a mindset oriented toward an effective management of devices and personnel, which together allow exploiting from the beginning the improvements of a new generation of devices. In fact, given the rapid progress of scientific and technological research, the situation could significantly improve in few years. Research is exploring ways to improve the effectiveness of the automatic devices with features that enhance their "awareness" during the resuscitation process and their ability to adapt in real time to the clinical situation of the patient. For example, Sundermann et al. [20] showed that the mean arterial pressure and the qECG metric median slope of the ventricular fibrillation waveform can be used as biosignals to control rate and depth of compression. Zhang et al. [21] developed a closed-loop controller for a trade-off between the improvement of the blood perfusion and the risk of ribs fracture.

Computer models are another way to improve the effectiveness of the automatic devices, probably the best one. Commercial software allows creating a 3D representation of the human body, and to describe it as an environment in which the different physics (mechanical and fluid dynamic above all) interact to give the global physiological response to stimulation. Therefore, simulating the anelasticity of tissues and the compliance of the rib cage, the model can calculate not only the mechanical behaviour of the chest, but also the hemodynamic effect generated by the way the chest is compressed: for example, where the force/pressure is applied, or how it is applied over each cycle, taking into account the effect of drug and other treatments. In this way the effectiveness of the devices can be thoroughly tested with computational experiments. Finally, computer models can compute the stresses in tissues and ribs, and therefore help to evaluate the safety of the device and its working parameters. If this computation could be done during the resuscitation itself, from signals gathered by sensors, it could predict the onset of injuries and prevent most of them.

In short, since it is based on technology, automatic CPR is susceptible of great improvement, because it can profit from the ever increasing miniaturization and efficiency of sensors, actuators, and processors. More powerful on-board processors allow controlling the massage with more sophisticated alghoritms, therefore delivering a stimulation consistent with the clinical condition of the patient.

\section{References}

1. Wik L, Olsen JA, Persse D, Sterz F, Lozano M, et al. (2014) Manual vs. integrated automatic load-distributing band CPR with equal survival after out of hospital cardiac arrest. The randomized CIRC trial. Resuscitation 85(6): 741-748.

2. Rubertsson S, Lindgren E, Smekal D, Östlund O, Silfverstolpe J, et al. (2014) Mechanical chest compressions and simultaneous defibrillation vs conventional cardiopulmonary resuscitation in out-of-hospital cardiac arrest: the LINC randomized trial. JAMA 311(1): 53-61.

3. Perkins GD, Lall R, Quinn T, Deakin CD, Cooke MW, et al. (2015) Mechanical versus manual chest compression for out-of-hospital cardiac arrest (PARAMEDIC): a pragmatic, cluster randomised controlled trial. The Lancet 385(9972): 947-955.

4. Gates S, Lall R, Quinn T, Deakin CD, Cooke MW, et al. (2017) Prehospital randomised assessment of a mechanical compression device in out-ofhospital cardiac arrest (PARAMEDIC): a pragmatic, cluster randomised trial and economic evaluation. Health Technol Assess 21(11): 1-176.

5. Westfall M, Krantz S, Mullin C, Kaufman C (2013) Mechanical versus manual chest compressions in out-of-hospital cardiac arrest: a metaanalysis. Crit Care Med 41(7): 1782-1789.

6. Brooks SC, Hassan N, Bigham BL, Morrison LJ (2014) Mechanical versus manual chest compressions for cardiac arrest. Cochrane Database Syst Rev (2): CD007260.

7. Bonnes JL, Brouwer MA, Navarese EP, Verhaert DV, Verheugt FW, et al. (2016) Manual cardiopulmonary resuscitation versus CPR including a mechanical chest compression device in out-of-hospital cardiac arrest: a comprehensive meta-analysis from randomized and observational studies. Ann Emer Med 67(3): 349-360.e3.

8. Couper K, Yeung J, Nicholson T, Quinn T, Lall R, et al. (2016) Mechanical chest compression devices at in-hospital cardiac arrest: A systematic review and meta-analysis. Resuscitation 103: 24-31.

9. Forti A, Zilio G, Zanatta P, Ferramosca M, Gatto C, et al. (2014) Full recovery after prolonged cardiac arrest and resuscitation with mechanical chest compression device during helicopter transportation and percutaneous coronary intervention. J Emerg Med 47(6): 632-634.

10. Remino C, Baronio M, Pellegrini N, Aggogeri F, Adamini R (2018) Automatic and manual devices for cardiopulmonary resuscitation: A review. Advances in Mechanical Engineering 10(1): 1-14.

11. Babbs CF (1999) CPR techniques that combine chest and abdominal compression and decompression: hemodynamic insights from a spreadsheet model. Circulation 100(21): 2146-2152.

12. Havel C, Berzlanovich A, Sterz F, Domanovits H, Herkner H, et al. (2008) Safety, feasibility, and hemodynamic and blood flow effects of active compression-decompression of thorax and abdomen in patients with cardiac arrest. Crit Care Med 36(6): 1832-1837.

13. Jung E, Lenhart S, Protopopescu V, Babbs C (2008) Optimal control applied to a thoraco-abdominal CPR model. Math Med Biol 25(2): 157170.

14. Babbs CF (2006) Biophysics of cardiopulmonary resuscitation with periodic z-axis acceleration or abdominal compression at aortic resonant frequencies. Resuscitation 69(3): 455-469.

15. Aliverti A, Bovio D, Fullin I, Dellacà RL, Lo Mauro A, et al. (2009) The abdominal circulatory pump. PLoS One 4(5): e5550.

16. Aliverti A, Uva B, Laviola M, Bovio D, Lo Mauro A, et al. (2010) Concomitant ventilatory and circulatory functions of the diaphragm and abdominal muscles. J Appl Physiol 109(5): 1432-1440.

17. Steen S, Liao QM, Pierre L, Paskevicius A, Sjöberg T (2003) The critical importance of minimal delay between chest compressions and subsequent defibrillation: a haemodynamic explanation. Resuscitation 58(3): 249-258. 
18. Ong MEH, Annathurai A, Shahidah A, Leong BS, Ong VY, et al. (2010) Cardiopulmonary resuscitation interruptions with use of a loaddistributing band device during emergency department cardiac arrest. Ann Emerg Med 56(3): 233-241.

19. Marti J, Hulme C, Ferreira Z, Nikolova S, Lall R, et al. (2017) The costeffectiveness of a mechanical compression device in out-of-hospital cardiac arrest. Resuscitation 117: 1-7.
20. Sundermann ML, Salcido DD, Koller AC, Menegazzi JJ (2016) Feasibility of biosignal-guided chest compression during cardiopulmonary resuscitation: a proof of concept. Acad Emer Med 23(1): 93-97.

21. Zhang G, Wu TH, Song ZX, Wang H, Lu H, et al. (2015) A mechanical chest compressor closed-loop controller with an effective trade-off between blood flow improvement and ribs fracture reduction. Med Biol Eng Comput 53(6): 487-497.

\section{Your next submission with Juniper Publishers} will reach you the below assets

- Quality Editorial service

- Swift Peer Review

- Reprints availability

- E-prints Service

- Manuscript Podcast for convenient understanding

- Global attainment for your research

- Manuscript accessibility in different formats

( Pdf, E-pub, Full Text, Audio)

- Unceasing customer service

Track the below URL for one-step submission https://juniperpublishers.com/online-submission.php 